\title{
Development of a Plastic Dosimeter for Industrial Use with High Doses
}

\author{
M. El-Kelany, S. Ebraheem and S. M. Gafar
}

Radiation Protection Dept., National Centre for Radiation Research and Technology, P. O. Box; 29 Nasr City, Cairo, Egypt.Email:dr.moosh@hotmail.com

\begin{abstract}
THESE FILMS contain a mixture of two dyes namely bromothymol blue (BTB) and methyl orange (MO) indicator with different concentrations of alanine in poly(vinyl alcohol) (PVA). The colour of this film changes from green to colourless by irradiation due to the consequent lowering of $\mathrm{pH}$ of the film caused by the $\mathrm{H}^{+}$generated from radiolysis of $\alpha$-alanine. The response of these films can be modified by changing the $\alpha$-alanine concentration and the ratio of the two dyes. As a result, these films can be used as a dosimeter in high dose range. The dosimetric parameter e.g., dose response, effect of relative humidity, pre- and post-irradiation stability of these films are investigated.

Keywords: Bromothymol blue, methyl orange, poly(vinyl alcohol, gamma-rays dosimeter, $\alpha$-alanine.
\end{abstract}

Radiation bleachable organic dyes were widely investigated (Ebraheem et al., 2005). For dose monitoring in radiation processing, the polymeric dyed flexible films are considered to be most commonly used as dosimeters, indicators (Abdel-Rehim and Abdel-Fattah, 1993 and Abdel-Rehim et al., 1993) and for monitoring the absorbed dose delivered by electron beams and gamma-rays (Kovaces et al., 2002). Ebraheem (2007) studied the effect of alanine on bromophenol blue polymeric films for radiation dosimetry applications, that the dyed polymeric films prepared by simple technique of casting aqueous solution of PVA containing bromophenol blue on horizontal glass plate are useful for high dose dosimetry applications, that the colour has a variable absorbance with applied dose in the range from 1-35 kGy. Ueno (1988) developed a radiation dosimeter from acid indicators by coating a high molecular wt polymer support (e.g. polyester film) with a composition containing a halogen-containing polymer (e.g. PVC), a pigment which changes colour with the changes of $\mathrm{pH}$ and basic material (e.g. $\mathrm{KOH}$ in $\mathrm{EtOH}$ ). A chlorine-containing polymer is not 
necessary for this reaction to occur. A similar colour change can be produced in chloro-alkanes are present in the dye containing matrix (Whittaker, 1988). A system of interest in dosimetry, since it offers the possibility of a very sensitive dosimeter, is an aqueous, air-saturated, solution of chloral hydrate containing 0.001-1 $\mathrm{M} \mathrm{CCl}_{3} \mathrm{CH}(\mathrm{OH})_{2}$. These solutions give acid products (mainly $\mathrm{HCl}$ ) with G-values ranging from $10 \mathrm{~mol} / \mathrm{J}$ to several hundred depending upon the conditions. The high yields, concentration and dose-rate dependencies are indicative of the chain reaction initiated by radical attack upon the chloral hydrate. For routine dose monitoring in radiation processing, the polymeric dyed flexible films are considered to be the most common ones as dosimeters, dose labels and indicators (Abdel-Rehim and Abdel-Fattah, 1993, Abdel-Rehim et al., 1985 \& 1991 and McLaughlin et al., 1989). These dyed PVA systems are bleached by irradiation, the extent to which the colour changes is used for determining the absorbed dose. Based on the idea of mixing, in PVA two dyes having different sensitivities to radiation, and a label dosimetry system has been developed (Abdel-Rehim and Abdel-Fattah, 1993). A new radiation sensitive indicator consisting of PVA film containing PH-indicating dye and watersoluble chlorine containing substance has been developed by (Abdel-Fattah $e t$ al., 1996).

The current work deals with the investigation of a new PVA film to enable their use in high radiation processing applications.

\section{Experimental}

\section{Preparation of stock solutions (BTB, MO-mix) dyes}

The stock solution of the indicator was prepared by dissolving $0.04 \mathrm{~g}$ of both BTB and MO (product of CHMPOL, Czech Republic and RIEDELDEHAEN,Germany) in $25 \mathrm{ml}$ distilled water. These two stock solutions were used in the preparation process of mixed dye dosimetry film.

\section{Preparation of (BTB, MO)/ PVA mixed dye films}

A $10 \mathrm{~g}$ of fully hydrolyzed PVA powder (99-100\%) (from Sigma) was well dissolved in $250 \mathrm{ml}$ doubly distilled water at about $60^{\circ} \mathrm{C}$. The solution was stirred at that temperature for about $48 \mathrm{~h}$ and after cooling, it was divided into four parts, $\alpha$-alanine $(44.6,66.6$ and $99.6 \mathrm{phr}$ ) was added to three parts of 
polymer solution. The same amounts of BTB and MO indicators were added to four parts of the polymer solutions. All four solutions were kept well-stirred at room temperature for about $4 \mathrm{~h}$ in order to obtain a uniformly mixed solution. Each solution was poured into a horizontal glass plate and dried at room temperature for about $48 \mathrm{~h}$. The different concentration of $\alpha$-alanine is $44.6,66.6$ and $99.6 \mathrm{phr}$. After drying, the films were cut into $1 \times 1 \mathrm{~cm}$ pieces, stored and used for different investigations. The thickness of the films was found to be $0.045 \pm 0.005 \mathrm{~mm}$ of variation coefficient $(1 \sigma)$.

\section{Results and Discussion}

\section{Absorption pectra}

The absorption spectra for the PVA film containing a mixture of $0.533 \mathrm{phr}$ of BTB and MO were recorded before and after irradiation. Fig. 1. shows the absorption spectra of unirradiated and irradiated films with different absorbed doses. The absorption spectrum of these films shows two absorption bands peaking at 622 and $405 \mathrm{~nm}$. The first one is characteristic of the blue colour of BTB and the second is characteristic of the yellow colour of MO indicator. The amplitude of these bands decreases gradually with the increase of dose of $\gamma$-ray photon.

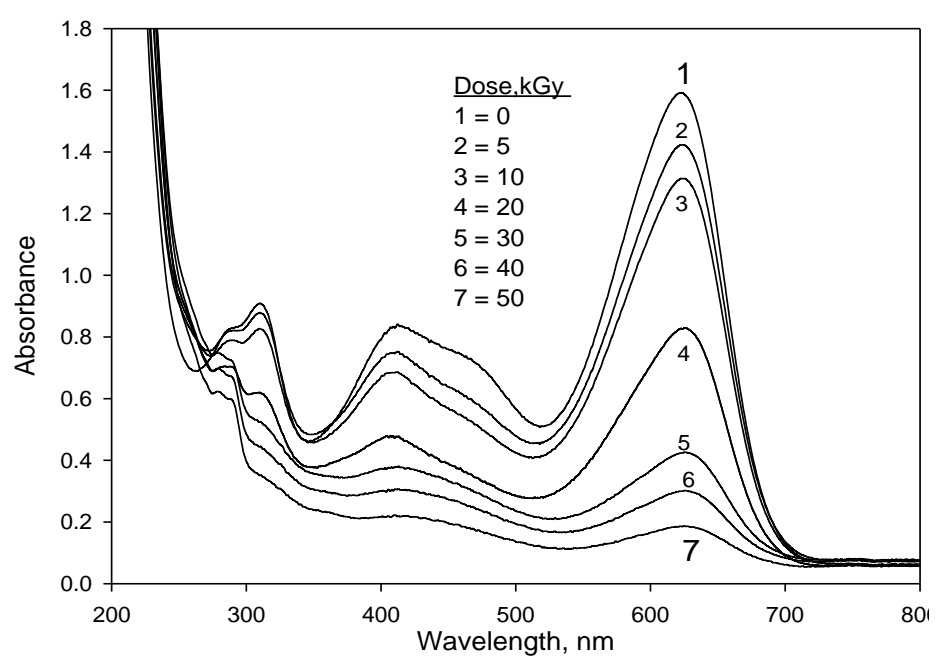

Fig. 1. The absorption spectra of (BTB-MO)/ PVA films unirradiated and irradiated to different absorbed doses.

Egypt. J. Rad. Sci. Applic., Vol. 24, No. 1 (2011) 
Fig. 2. Shows the absorption spectra of BTB-MO/ PVA films unirradiated and irradiated to different doses. These films contain $66.6 \mathrm{phr} \alpha$-alanine. Also, the amplitude of these bands decreases gradually with increase of dose of $\gamma$-ray, the decrease in absorbance at $622 \mathrm{~nm}$ is due to combined effects of radiationinduced bleaching of the indicator and change in $\mathrm{pH}$ of the medium. It was found that the useful dose range of these films 30-100 kGy. It was noticed that the addition of $\alpha$-alanine makes the dose range longer or ascend the dose range from $30 \mathrm{kGy}$ to $150 \mathrm{kGy}$ depending on $\alpha$-alanine concentration. This is due to the effect of irradiation upon the structure of $\alpha$-alanine, $\mathrm{CH}_{3}-\mathrm{CH}\left(\mathrm{NH}_{2}\right) \mathrm{COOH}$ which forms positive cation $\mathrm{NH}_{4}{ }^{+}$and negative anion $\mathrm{CH} 3 \mathrm{C}[\mathrm{dot}] \mathrm{HCOO}^{-}$, this addition leads to increase the colour intensity of the film.
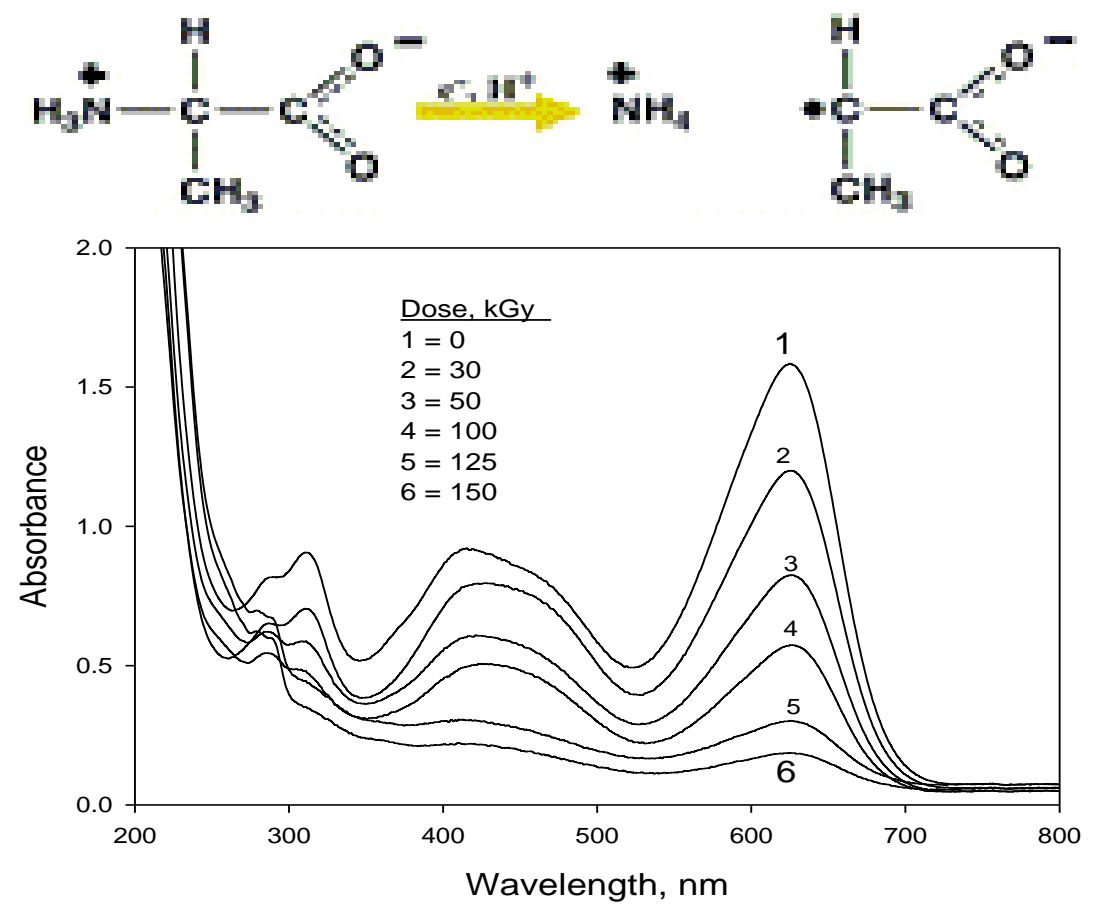

Fig. 2. The absorption spectra of (BTB-MO)/ PVA films unirradiated and irradiated to different absorbed doses. $[\alpha$-alanine $]=66.6 \mathrm{phr}$.

\section{Response curves}

Fig. 3. Shows the dose response curves of three films containing equal concentration of two combined dyes BTB and MO (0.533 phr) in the response Egypt. J. Rad. Sci. Applic., Vol. 24, No. 1 (2011) 
of different concentration of $\alpha$-alanine (44.6, 66.6 and $99.6 \mathrm{phr}$ ). The dose response curves were established in terms of change in optical density measured at $622 \mathrm{~nm}$ per unit thickness $\Delta \mathrm{A} \mathrm{mm^{-1 }}$ against the absorbed dose $\left(\Delta \mathrm{A}=\mathrm{A}_{\mathrm{o}}-\mathrm{A}_{\mathrm{i}}\right)$, where $A_{o}$ and $A_{i}$ are values of optical absorbance at $622 \mathrm{~nm}$ for unirradiated and irradiated films. It can be noticed that all curves show the same trend, but they different in the initial slope value, which increases with increase of $\alpha$-alanine concentration. This result reflects the sensitizing effect of $\alpha$ - alanine on radiation induced bleaching of BTB.

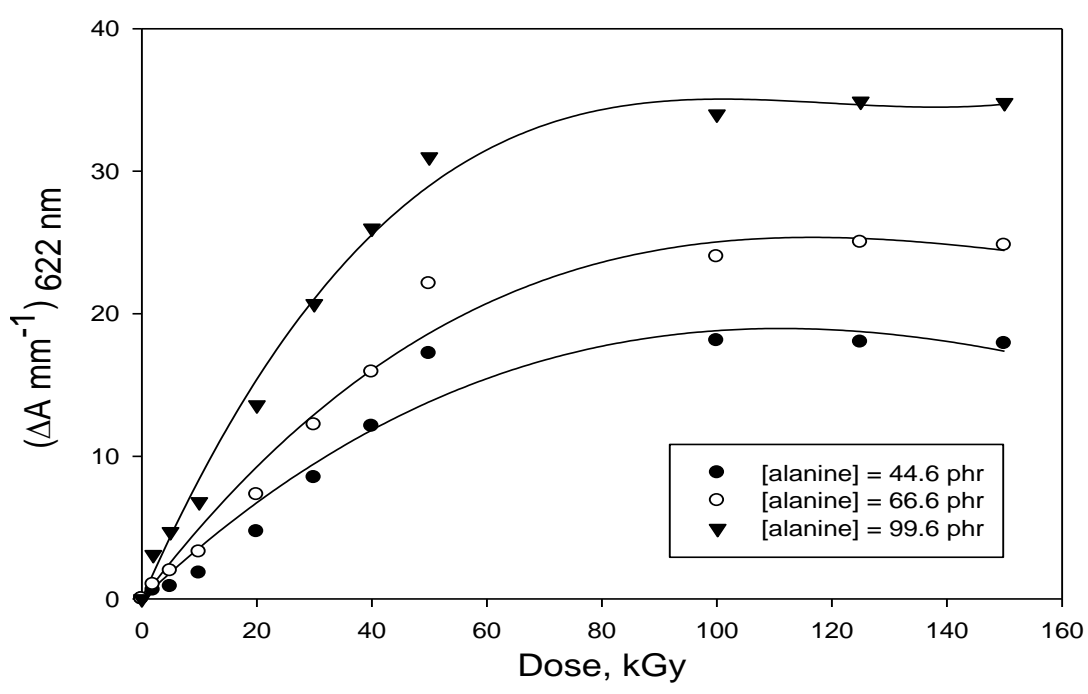

Fig. 3. Change of absorbance at $622 \mathrm{~nm}$ as a function of absorbed dose of (BTBMO)/PVA films with different concentrations of $\alpha$-alanine.

\section{Humidity during irradiation}

The effect of relative humidity $(\mathrm{RH})$ during irradiation on the response of BTB-MO/ PVA films was investigated by irradiating the films $0.533 \mathrm{phr}$ BTB-MO and $66.6 \mathrm{phr} \alpha$-alanine to dose of $30 \mathrm{kGy}$ at different relative humidities. The different relative humidities were maintained by using different saturated salt solutions. The films were stored before irradiation for three days period under the same relative humidity conditions as when irradiated, so equilibrium moisture content in dosimeter is established during irradiation. Fig. 4. shows the variation in response $\left(\Delta \mathrm{A} . \mathrm{mm}^{-1}\right)$ at $622 \mathrm{~nm}$ as a function of percentage relative humidity during irradiation relative to the response value 
$33 \%$ relative humidity. The response is flat for relative humidities in the range of (10-54\%) with reduced sensitivity at higher humidities. It can be concluded that BTB-MO/PVA films can be used at negligible humidity effects on response in intermediate range of humidity from (10-54\%) to avoid the effects of high humidity levels. It may also be possible to reduce the humidity influence by using sealed films under controlled intermediate humidity conditions.

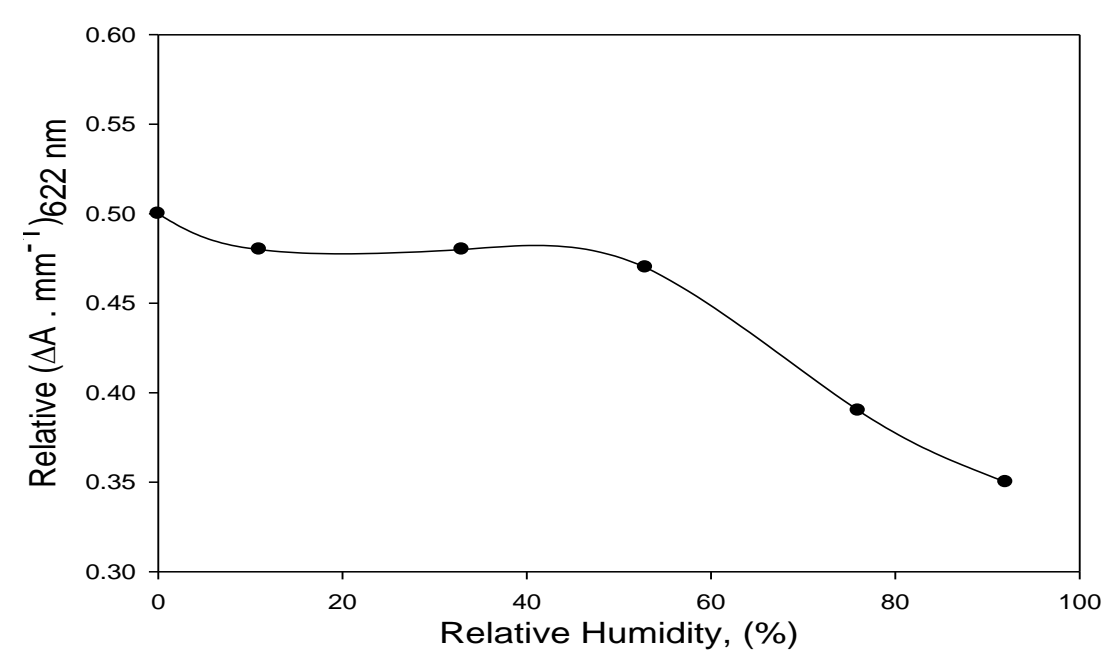

Fig. 4. Variation of response of (BTB-MO)/ PVA films (at $622 \mathrm{~nm}$ ) as a function of relative humidity during irradiation, where response in $\Delta \mathrm{A} . \mathrm{mm}-1$ at $30 \mathrm{kGy}$.

\section{Post-irradiation Stability}

BTB-MO/ PVA films $([\alpha$-alanine $]=66.6 \mathrm{phr})$ irradiated to $30 \mathrm{kGy}$ were stored immediately after irradiation, one dark and the other in indirect sunlight, both at room temperature.

The films were measured spectrophotometrically at $\lambda_{\max }=622 \mathrm{~nm}$, wavelength at different intervals of time during the post-irradiation storage period of 60 days. Fig. 5. shows the relative to the value to zero time, as a function of storage time. It can be seen that $\Delta \mathrm{A}_{622}$ of the film stored in light decreases during the first two days after irradiation then tends to stabilize. On the other hand, the film stored in dark shows excellent stability overall the 60 days storage period.

Egypt. J. Rad. Sci. Applic., Vol. 24, No. 1 (2011) 


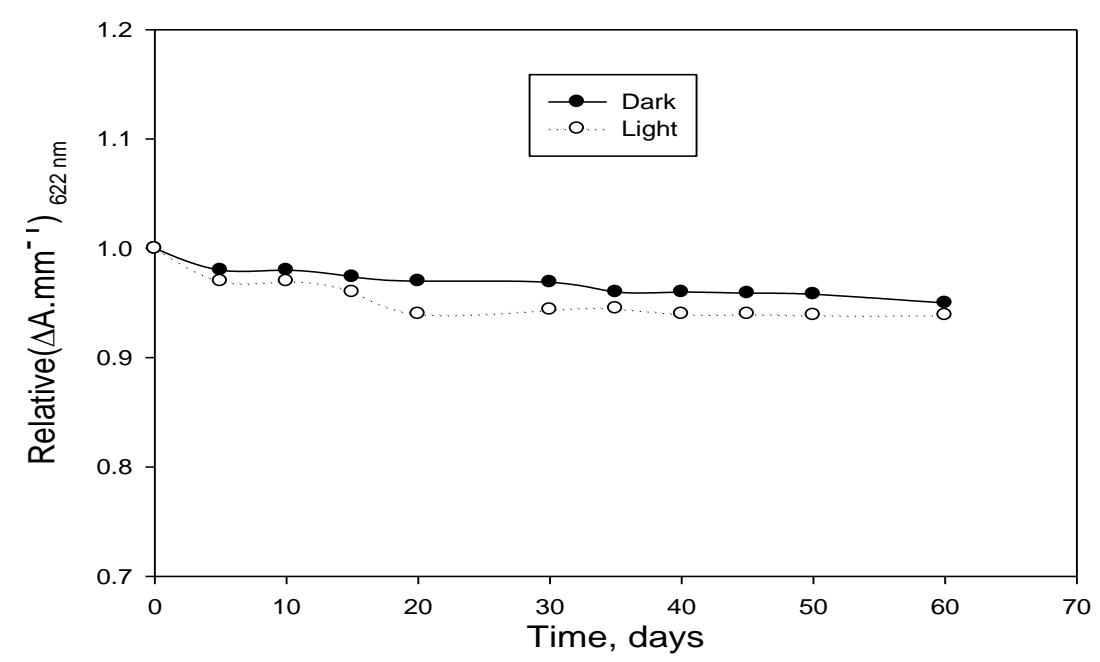

Fig. 5. Post-irradiation stability of (BTB-MO)/ PVA films stored under different storage conditions.

\section{Assessment of uncertainties}

To be meaningful, a measurement of gamma ray shall be accompanied by an estimate of the uncertainty in the measured value. Factors contributing to the total uncertainty may be separated into two types, type A and type B (ISO/ASTM, 2002). The first factor is associated mainly with the measuring equipment and the films and the second is mainly related to the calibration.

The reproducibility of the Unicam UV-4 spectrophotometer was determined by reading the absorbance value (at $600 \mathrm{~nm}$ wavelength and absorbance level 0.8) of irradiated films several times (ten readings per film). From the data obtained, it was found that the coefficient of variation $(1 \sigma)$ is \pm $0.2 \%$, reflecting the precision of the spectrophotometer. The reproducibility of the Minitest thickness gauge was determined by reading the thickness value for BTB-MO/ PVA films several times (ten readings per film). From the data obtained, it was found that the coefficient of variation $(1 \sigma)$ is $\pm 0.9 \%$. The reproducibility of the measurements of several films (10 times for each film) was found to be $0.88 \%(1 \sigma)$. On the other hand, the type A uncertainties (at one standard deviation, i.e. $1 \sigma$ ) arising during calibration over the useful response 
range were found to be $\pm 2.2 \%$ (ASTM, 1996). The combining all the components in quadrature at one standard deviation $1 \sigma$ as follows:

$$
\mathrm{U}_{\mathrm{c}}=\sqrt{ }(0.2)^{2}+(0.9)^{2}+(2.2)^{2}+(0.88)^{2}=2.54 \% .
$$

The combined uncertainty $\left(\mathrm{U}_{\mathrm{c}}\right)$ (at two standard deviations, i.e. $2 \sigma$, approximately equal to a $94 \%$ confidence level) is found by multiplication of $\mathrm{U}_{\mathrm{c}}($ at $1 \sigma$ ) by two. Hence the combined uncertainty using BTB-MO/ PVA film is $5.09 \%$.

\section{Conclusion}

Films made of PVA dyed with BTB-MO mixture containing different concentration of $\alpha$-alanine are useful radiation dosimeters in the dose range 5-100 kGy, the colour of these films changes from green to colourless. The films are highly stable for long times after irradiation under different storage conditions and are not affected by the humidity changes in the intermediate range of the relative humidity $(10-54 \%)$. These properties suggest them to be useful for routine monitoring and dose mapping in radiation processing. They are easy to prepare in a laboratory and do not require toxic solvents in the preparation.

\section{References}

Abdel-Fattah, A. A., Ebraheem, S., El-Kelany, M. and Abdel-Rehim, F. (1996) High-dose film dosimeters based on bromophenol blue or xylenol orange dyed polyvinyl alcohol. Appl. Radiat. Isot., 47, 345.

Abdel-Rehim, F. and Abdel-Fattah, A. A. (1993) A thin-film radiation monitoring label and dosimetery system. Appl. Radiat. Isot.,. 44, 1047.

Abdel-Rehim, F., El-Sawy, N. M. and Abdel-Fattah, A. A. (1993) Dyed grafed films for large-ndose radiation dosimetry. Appl. Radiat. Isot., 44, 1055.

Abdel-Rehim, F. and Abdel-Fattah, A. A. (2003) A thin-film radiation monitoring label and dosimetry. Appl. Radiat. Isot., 44, 1047.

Abdel-Rehim, F., Miller A. and McLaughlin, W. L. (1985) Response of radiation monitoring labels to gamma rays. Radiat. Phys. Chem., 25, 797.

Abdel-Rehim, F., Soliman, F. A. S., Ebraheem, S. and Souka, N. (1990) Evaluation of a commercial red-dyed plastic film for gamma irradiation monitoring. Appl. Radiat. Isot., 41, 700.

Ebraheem, S. and Beshir, W. B.. (2005). investigation of dyed film based on 2, 6dichlorophenol dyed poly (vinyl alcohol) and poly (vinylbutyral) for possible use in high-dose processing dosimetery. Arab. J. Nucl. Sci. Applic., 38, 1.

Egypt. J. Rad. Sci. Applic., Vol. 24, No. 1 (2011) 
Kovacs, A. and Ebraheem, S. (2002) A new dyed poly(vinyl alcohol) film for highdose application. Radiat. Phys.Chem., 63, 807.

ISO/ASTM (2002) Standard Guide for Estimating Uncertainties in Dosimetry for Radiation Processing, ISO/ASTM 51707: (E), ISBN 0-8031-2848-7.

McLaughlin, W. L., Boyd, A. W., Chadwich, K. H., McDonald, J. C. and Miller, A. (1989) Dosimetry Radiation Processing. (London: Taylor \& Francis), pp. 33

Ueno, K. (1988) Development of a plastic dosimeter for industrial use with high doses. Radiat. Phys. Chem., 31, 467.

Whittaker, B. (1988) The GAMMACHROME YR system. In Dosimetery and Control Processing, NPL Report RS (RXT) 97, Symposium of UK Panel on Gamma Ellectron Irradiation (Teddington, UK: National Physical Laboratory), 18, 533.

(Received: 05/12/2011;

accepted: 28/12/2011

Egypt. J. Rad. Sci. Applic., Vol. 24, No. 1 (2011) 


$$
\begin{aligned}
& \text { تطـوير افـلام بلاسـتيكية لقيـاس الجرعـات الاشــعاعية العاليـة }
\end{aligned}
$$

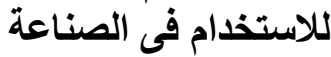

$$
\begin{aligned}
& \text { مشيرة الكيلانى و سيف ابراهيم و سامح محمد جعفر }
\end{aligned}
$$

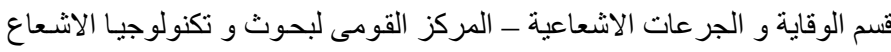

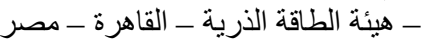

هذة الأفلام المتبلمرة المحضرة من عديد الفينيل كحول و التى تحتوى على تلى

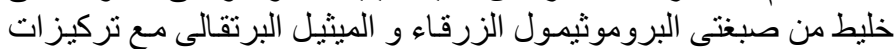

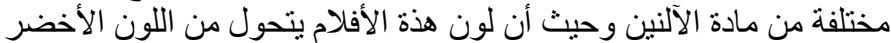

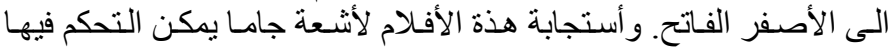

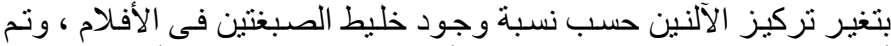

أيضا در اسة نسبة الرطوبة و ثبات الأفلام قبل و بعد التثتعيع بأثتعة جاما.

Egypt. J. Rad. Sci. Applic., Vol. 24, No. 1 (2011) 